\title{
COMO NEGAR UM NOME ${ }^{1,2}$
}

\author{
João Vergílio Gallerani Cuter (USP) ${ }^{3}$ \\ jv-cuter@uol.com.br
}

Resumo: O nome, no Tractatus Logico-Philosophicus, é sempre uma função proposicional. Wittgenstein modifica radicalmente a oposição fregiana entre entidades saturadas e insaturadas. Toda parte sentencial que não seja ela própria uma sentença é insaturada. A proposição é, portanto, uma síntese de funções proposicionais. O nome é o caso-limite de função proposicional. Como qualquer função proposicional, ele pode perfeitamente ser negado.

Palavras-chave: filosofia da linguagem, filosofia da lógica, negação, função proposicional, nome, Wittgenstein, Tractatus Logico-Philosophicus.

"Toda parte da proposição que caracteriza seu sentido", diz Wittgenstein, "eu chamo de uma expressão (um símbolo)" (3.31). Após afirmar que a proposição também será considerada por ele uma expressão (vale dizer, uma "parte" de si mesma que "caracteriza seu sentido"), o autor fornece uma caracterização complementar. Wittgenstein diz que uma expressão é tudo aquilo que, "sendo essencial para o sentido da proposição, as proposições podem ter em comum umas com as outras". Essa última característica é enfatizada nos

\footnotetext{
${ }^{1}$ Recebido: 25.02.2010/Aprovado: 03.08.2010/Publicado on-line: 08/12/2010.

${ }^{2}$ Este texto procura dar um desenvolvimento a uma ideia expressa no ensaio introdutório do prof. Luiz Henrique Lopes dos Santos da edição brasileira do Tractatus Logico-Philosophicus. O trecho relevante pode ser encontrado na pagina 71 da referida edição, no parágrafo que começa com as seguintes palavras: "Esta maneira de traçar a distinção entre sinal e símbolo...".

${ }^{3}$ João Vergílio Gallerani Cuter é Professor-adjunto do Departamento de Filosofia da Universidade Estadual de São Paulo, São Paulo, Brasil e pesquisador do CNPq.
} 
três aforismos seguintes: uma expressão é "a marca característica comum de uma classe de proposições" (3.311), e é representada, por isso, pela "forma geral das proposições que ela caracteriza" (3.312); ela é "apresentada por uma variável, cujos valores são as proposições contendo a expressão" (3.313).

É claro, em primeiro lugar, que Wittgenstein está falando aqui de proposições completamente analisadas. A teoria das descrições de Russell fez com que, na presença de certos pressupostos, a noção de "parte proposicional" deixasse de possuir um critério meramente visual de identificação. A partir do artigo sobre a denotação (1905), as "partes" proposicionais passarão a ser objeto de uma descoberta, e não de uma constatação. Serão o resultado de um longo processo de análise. A ideia, aliás, não era nova. Em certo sentido, ela é inseparável do projeto logicista como um todo. Muito antes de 1905, a conceitografia de Frege já havia exibido complexidades lógicas em certas proposições que não encontram expressão na linguagem cotidiana. "Todo homem é mortal", por exemplo, pode ser encarada, de um ponto de vista lógico, como o preenchimento de um quantificador universal ("para todo $\left.x^{\prime \prime}\right)$ por uma função condicional de primeira ordem ("se $x$ é homem, então $x$ é mortal"). "Há 3 pessoas nesta sala" exige o uso de pelo menos quatro quantificadores para ser reescrita no simbolismo da conceitografia. As "partes" lógicas da proposição analisada nada têm a ver com as palavras que utilizamos em sua expressão cotidiana. Por outro lado, quando lida com sentenças da linguagem cotidiana, Frege raramente sente-se atraído pelo expediente de substituir uma forma de expressão por outra. Os artigos da década de 90 exemplificam bem essa tendência. Quando Frege pergunta-se a respeito 
do sentido e da referência de expressões como "a Estrela da Manhã", ele certamente não desconhece os artifícios técnicos que podem ser usados para expressar a unicidade implícita no artigo singular. Foi ele, afinal de contas, e não Russell, o inventor desses artifícios ${ }^{4}$. Falta-lhe, talvez, a percepção de que o artigo singular é uma excelente ocasião para a aplicação dos quantificadores. Acima de tudo, porém, falta-lhe a motivação teórica que, no âmbito da aritmética, levou-o a procurar uma expressão alternativa para sentenças aparentemente tão simples quanto " $3<5$ ". Ao invés disso, Frege supõe que a expressão "a Estrela da Manhã" tenha, de fato, um sentido e uma referência, e que a proposição "A Estrela da Manhã é Vênus" pode ser vista como uma equação, e não como uma afirmação de existência.

É interessante lembrar que, antes de escrever o artigo sobre a denotação, o próprio Russell esboçara uma semântica até certo ponto desatrelada da análise lógica que ela herdara de Frege. Nos Principles of Mathematics, Russell toma as expressões "um homem", "todo homem", "cada um dos homens", "algum homem", "o homem", etc., como partes proposicionais com sentido autônomo. A análise lógica limita-se, por assim dizer, a "sugerir" as denotações apropriadas em cada caso, caracterizadas por diferentes modos de seleção aplicados ao conjunto dos homens ${ }^{5}$. Existe ali, como existia em Frege, uma teoria composicional do significado, mas suas relações com a sintaxe lógica da linguagem são confusamente percebidas, ou pobremente exploradas. Em 1905, isso muda completamente. Aos olhos de Russell, a principal vantagem da "teoria dos símbolos incompletos",

\footnotetext{
${ }^{4}$ Cf. Os Fundamentos da Aritmética, \$55.

${ }^{5}$ Cf. The Principles of Mathematics, §§58-65.
} 
que ele apresenta em seu famoso artigo, é que ela nos permite assumir a teoria composicional do significado em toda a sua radicalidade. Os tijolos sintáticos exibidos pela análise lógica são também os tijolos semânticos - coisa que não acontecia nos Principles. Além disso, a teoria proposta por Russell em "On denoting" abre um horizonte no qual se entrevê a possibilidade de dar um tratamento adequado aos paradoxos que haviam levado Frege a duplicação do conteúdo semântico das proposições e das partes proposicionais.

Como eu já disse, o artifício técnico subjacente à teoria das descrições não foi criado por Russell. Frege conhecia perfeitamente bem o procedimento de análise que redunda na afirmação de que existe exatamente um objeto satisfazendo uma dada propriedade. Russell limitou-se a utilizar o expediente sem citar a fonte. No entanto, justiça seja feita, sua utilização abriu um horizonte de análise completamente novo, que o próprio Russell jamais conseguiria explorar completamente. O Tractatus é, de certo modo, o grande beneficiário da teoria.

$\mathrm{O}$ que Wittgenstein percebe perfeitamente, em primeiro lugar, é o sentido profundo da teoria. $\mathrm{O}$ que a teoria das descrições de Russell demonstra não é apenas que a forma lógica de uma proposição não precisa coincidir com sua forma superficial. Isso Frege já havia demonstrado de modo convincente. Russell mostra que, se a significação de uma expressão designadora depender da verdade de uma proposição $p$ qualquer, então (i) a expressão não designa coisa nenhuma e (ii) toda proposição em que ela ocorre afirma, entre outras coisas, a ocorrência de p. O que Wittgenstein fez, nesse ponto, foi forçar a teoria das descrições a ser consequente com seus pressupostos, sendo um deles, como vimos, a teoria composicional do significado. Abandonando 
a duplicidade semântica do sentido e da referência, Russell é levado a identificar o significado de qualquer expressão designadora com aquilo que é designado por ela. $\mathrm{O}$ princípio de composicionalidade exige que o sentido sentencial (seja lá ele o que for) seja univocamente determinado pelos significados dessas expressões. Ora, a teoria das descrições irá obrigar-me a retirar do rol das expressões designadoras qualquer expressão cuja referência dependa da verdade de uma proposição. Mas para que o princípio de composicionalidade se mantenha em pé, é preciso que existam expressões designadoras que já não tenham nenhum conteúdo descritivo. Deve haver, portanto, uma análise final das proposições da linguagem, na qual toda e qualquer expressão designadora possua o tipo de simplicidade lógica que o Tractatus associará aos nomes. Uma proposição está completamente analisada quando todas as suas expressões designadoras são "nomes" no sentido lógico do termo. A teoria de Russell apontava, inequivocamente, no sentido da tese tractariana de uma análise final das proposições da linguagem. Feita essa análise, saberíamos exatamente quais são as "partes" componentes de todo e qualquer discurso.

Como sabemos, no entanto, Russell transformou sua teoria dos tipos em um atalho que economizava quase todo o caminho da análise. Não foi preciso ir descendo degrau a degrau até os fundamentos últimos do sentido. A teoria dos tipos já nos contava, desde a Introdução dos Principia, quase todo o enredo da ontologia de Russell. A substância do mundo, para Russell, está disposta em uma hierarquia retorcida que pode ser pensada como um edifício com infinitos andares. No primeiro andar, estão os indivíduos, cuja natureza exata a epistemologia ficaria encarregada de determinar. No segundo andar, há infinitas espécies de pro- 
priedades de indivíduos, infinitas espécies de relações binárias entre indivíduos, infinitas espécies de relações ternárias entre indivíduos, e assim por diante. No terceiro andar, a confusão é infinitamente maior. Em uma de suas repartições, para que se tenha uma ideia, haveria infinitas espécies de relações com 27 lugares, dez dos quais preenchidos por indivíduos e os dezessete restantes por entidades vindas de diferentes repartições do andar de baixo ${ }^{6}$. Como se pode ver, nas mãos de Russell a navalha de Ockham transformava-se em uma espécie de varinha de condão. É bem verdade que essa ontologia ad hoc (cuja finalidade declarada era imunizar os Principia contra paradoxos) obedecia à velha máxima dos banquetes - "melhor sobrar que faltar". O sistema previa todas as possibilidades expressivas. A linguagem usaria as que fossem necessárias.

Voltemos, agora, à noção de "expressão". Uma expressão, ou símbolo, segundo o Tractatus, é qualquer parte da proposição que caracterize seu sentido. Tomemos, agora, uma proposição dos Principia e tentemos determinar o que viria a ser, nessa obra, uma expressão. Seja a proposição:

$$
F[f(x, y), a] v f(a, b)
$$

Trata-se de uma disjunção. No lado esquerdo da disjunção, temos uma função de segunda ordem (habitante, portanto, do terceiro andar do edifício) preenchida por dois argumentos. O primeiro argumento é uma função vinda do segundo andar, que toma dois indivíduos como argumento. Note-se que as letras "x" e "y" estão escritas aí em itálico, para indicar que elas não são variáveis. Elas estão apenas mar-

\footnotetext{
${ }^{6}$ Cf. Tractatus Logico-Philosophicus, 5.5541.
} 
cando o número e o tipo de argumento admitidos pela função "interna", isto é, pela função designada pelo "f" minúsculo, que ocupa, nesse contexto, o lugar do primeiro argumento da função designada pelo "F" maiúsculo. O segundo lugar de argumento dessa função é ocupado, aqui, pelo nome "a", que vem do andar térreo - é o nome de um indivíduo. No lado esquerdo da disjunção, temos uma proposição formada por uma função de segunda ordem, preenchida por dois argumentos. A função é a mesma que aparece no lado direito da disjunção - a função designada pela letra " $\mathrm{f}$ " minúscula. Nesse caso, ela não aparece como argumento. Ela toma argumentos apropriados. Assim, dois indivíduos - os designados pelas letras "a" (que também aparece como argumento da função F, no lado direito da disjunção) e "b". Para que a estrutura da proposição fique bem clara, vou representá-la utilizando os números correspondentes aos andares do edifício dos tipos:

$$
3\left[2_{1,1}, 1\right] \vee 2\left[1,1^{\prime}\right]
$$

O argumento " $2_{1,1}$ " tem subscritos marcando o tipo de argumentos que a função toma. $O$ argumento "1" não precisa de subscritos, pois entidades do primeiro andar (os "indivíduos") podem, segundo as convenções do condomínio russelliano, "ser argumentos", mas não "tomar argumentos". Já entidades do segundo andar (como $2_{1,1}$ ) podem tanto ser quanto tomar argumentos, conforme o caso. A aspa ao lado do último "1" marca a diferença entre os dois argumentos. Uma das regras básicas do edifício é que entidades de andares superiores só podem buscar argumentos nos andares inferiores. O regulamento pôs fim às desordens causadas pelas funções que tomavam a si mesmas como argumento.

Muito bem. Quais são as "expressões" componentes da 
proposição

$$
F[f(x, y), a] v f(a, b)
$$

vale dizer, quais são as "partes" que "caracterizam seu sentido"? Bem, se a expressão, como vem dito em 3.313, é "apresentada por uma variável, cujos valores são as proposições contendo a expressão", seria natural chamarmos de "expressão" o produto da substituição do sinal "b", na proposição (I), por uma variável do tipo apropriado - uma variável que percorra o domínio dos indivíduos. Utilizemos, nesse caso, a variável "y":

$$
F[f(x, y), a] v f(a, y)
$$

Note-se que, nesse caso, não escrevemos a variável em itálico, pois ela, aqui, é uma "variável real", vale dizer, uma variável livre, ocupando uma posição de substituição. $\bigcirc$ Tractatus chamaria uma expressão como (II) de "variável proposicional", já que seus valores são proposições. Entre esses valores, é claro, encontraremos a proposição (I) de que partimos.

Nesse momento começam a aparecer diferenças entre a lógica de Frege e de Russell e a lógica do Tractatus. Tanto Frege quanto Russell tenderiam a tomar "y", e não (II), como sendo uma "variável", e nenhum dos dois chamaria (II) de "variável proposicional". (II) seria vista antes como uma função proposicional contendo a variável "y". Conforme substituíssemos essa variável pelos argumentos adequados, obteríamos valores que, nesse caso, seriam valores proposicionais. Por outro lado, o que Frege e Russell chamariam

\footnotetext{
${ }^{7}$ Para facilitar a legibilidade, sempre escreverei as variáveis livres de uma fórmula em negrito.
} 
de "variável proposicional" seria uma letra esquemática utilizada para substituir proposições inteiras ${ }^{8}$. Podemos, por exemplo, exibir (I) como um exemplo da "forma proposicional disjuntiva" substituindo as proposições "F[ $\mathrm{f}(x, y)$, a ]" e "f(a,b)" pelas variáveis "p" e "q", obtendo assim o esquema "p v q"9. Essa pode parecer uma questão meramente verbal, mas não é. Para deixar isso claro, basta perguntarmos o que vem a ser o nome que, unindo-se a (II), resulta em (I). Para Frege e para Russell, o nome, nesse caso, é a letra "b". É "b" aquilo que deve ocupar o lugar da variável individual "y" em (II) para que obtenhamos a proposição (I). Para Wittgenstein, porém, o caminho que nos leva de (II) até (I) é completamente outro. Aquilo que o Tractatus chamaria de "variável", nesse momento, não é, como já vimos, a letra "y", mas sim toda a expressão (II). É (II) que, unida a um argumento, dá origem a uma proposição. A variável individual (ou "nome variável"), no Tractatus, carrega consigo toda a estrutura proposicional de que faz parte. Aliás, toda e qualquer variável apresenta exatamente a mesma possibilidade "toda variável", diz Wittgenstein, "pode ser concebida como variável proposicional" (3.314). E essa possibilidade não deve ser tomada apenas como um "modo de ver" a proposição, uma espécie de possibilidade "gestáltica", em meio a muitas outras. Ela reflete um aspecto profundo da análise wittgensteiniana da proposição. "É somente na proposição", diz

\footnotetext{
${ }^{8}$ No caso de Frege, essa afirmação deveria ser submetida a numerosas qualificações, em virtude do uso da função simbolizada pela "barra horizontal". O valor dessa função é sempre um valor de verdade. A asserção "| -[Se -(Sócrates), então - $(2+2=5)] "$, por exemplo, é uma asserção verdadeira, pois, devido à definição dada para a função "-(...)", a expressão "-(Sócrates)" deve ser vista como um nome do Falso. Cf., p.ex., Begriffsschrift, §2.

${ }^{9}$ A noção de "variável proposicional" está cercada de problemas que não serão discutidos aqui. $\mathrm{O}$ mais correto, se não estamos dispostos a usar quantificadores do tipo "para toda proposição p", seria tomar as letras "p", "q", etc., como meros expedientes abreviatórios.
} 
Wittgenstein no mesmo aforismo, "que uma expressão tem significado [Bedeutung]", refletindo assim, no nível das expressões, o dito fregeano que dá o motivo condutor de todo esse grupo de aforismos: "é apenas no contexto de uma proposição que um nome tem significado [Bedeutung]".

Ao dizer que toda variável pode ser concebida como uma variável proposicional, Wittgenstein está dizendo que essa "possibilidade" exibe uma característica importante da semântica das partes proposicionais - e, em especial, da semântica dos nomes. Assim como todo objeto tem uma "forma", dada por sua possibilidade de ocorrer em determinados estados de coisas e não em outros (2.0141), todo nome deve incorporar as possibilidades e impossibilidades sintáticas garantidoras do isomorfismo. Essas últimas devem ser tão constitutivas da natureza do nome quanto as possibilidades e impossibilidades ontológicas são constitutivas da natureza do objeto. Não há nome desvinculado dessa trama combinatória. Essa trama não se "acrescenta" ao nome, de fora, na forma de uma ordenação que se aplica sobre uma nomeação já constituída, mas é, pelo contrário, constitutiva da nomeação enquanto tal. Da mesma forma que (II) é aquilo que Wittgenstein chamaria, no sistema de Russell, de uma "variável individual", o nome correspondente a essa variável - o nome que se "acrescenta" a ela para formar a sentença (I) - jamais poderia ser a letra "b" sozinha. Da mesma forma que o "nome variável" é "F[ $f(x, y)$, a ] v f(a,y)", e não "y", o "nome constante" correspondente será

$$
\Phi[\varphi(x, y), \mathbf{x}] \vee \varphi(x, b)
$$

e não "b".

É isso, a meu ver, o que Wittgenstein está forçado a reconhecer ao afirmar que a expressão "caracteriza uma forma 
e um conteúdo" (3.31), pois "pressupõe a forma de todas as proposições nas quais ela pode ocorrer" (3.311); ou, ainda, quando afirma que a expressão é apresentada [dargestellt] pela "forma geral das proposições que ela caracteriza" (3.312). O "nome variável" (II) apresenta aquilo que é comum às proposições

$$
\begin{aligned}
& F[f(x, y), a] \mathbf{v} f(a, a) \\
& F[f(x, y), a] \mathbf{v} f(a, b) \\
& F[f(x, y), a] \mathbf{v} f(a, c),
\end{aligned}
$$

proposições que diferem (diríamos nós) pela presença de uma "letra" na última posição. A expressão (II) pressupõe, com efeito, todas as proposições dessa série e ocorre em todas elas. A expressão (II) é, na verdade, aquilo que todas elas têm em comum e é, nesse sentido, uma "variável proposicional cujos valores são essas proposições. Da mesma forma, não há como negar que (III) - isto é, " $\Phi[\varphi(x, y), \mathbf{x}]$ v $\varphi(x, b) "$ - seja uma expressão. Ela é uma variável proposicional, como (II). As proposições

$$
\begin{gathered}
F[f(x, y), a] \mathbf{v} f(a, b) \\
G[f(x, y), b] \mathbf{v} f(b, b) \\
F[g(x, y), c] \mathbf{v} g(c, b) \\
\text { etc. }
\end{gathered}
$$

são os valores dessa "variável", pois todas elas são proposições nas quais essa expressão poderia ocorrer. Nós diríamos que elas coincidem pela presença da letra "b" na última posição e identificaríamos o nome com essa letra. A rigor, porém, o que a designa não é o sinal "b", mas sim esse sinal 
associado a todas as regras sintáticas que permitem seu aparecimento em certos contextos sentenciais e não em outros. O nome está investido de suas possibilidades combinatórias e só designa enquanto "portador" dessas possibilidades. É isso, a meu ver, que Wittgenstein está expressando quando reutiliza o "dito contextual" fregiano no início dessa seção do Tractatus. Quando afirma que "é só no nexo proposicional que o nome tem significado", Wittgenstein está nos lembrando que o isomorfismo entre linguagem e mundo exige que as possibilidades combinatórias que permitem a inserção do nome naquele nexo proposicional são constitutivas do nome enquanto tal. O nome já "prefigurava", digamos assim, aquela possibilidade de inserção, e a expressão " $\Phi[\varphi(x, y), x]$ v $\varphi(x, b) "$ não é outra coisa senão isso - a nomeação do objeto, mais a prefiguração de um fato do qual esse objeto pode fazer parte.

Seria mais prudente - e, na verdade, mais exato - não chamarmos (III) de "nome", mas sim de "seção de um nome". Na proposição "F[ $f(x, y)$, a ] v f(a,b)", o que funciona como nome é, de fato, a expressão " $\Phi[\varphi(x, y), \mathbf{x}]$ v $\varphi(x, b) "$. Mas é evidente que tanto $" \Phi[\varphi(x, y), \mathbf{x}] \vee \varphi(x, b) "$ quanto $" \varphi(x, b) "$ são expressões que prefiguram possibilidades de ocorrência do mesmo nome. O mesmo poderia ser dito das expressões " $\varphi(x, b) "$ e " $\varphi(b, x) "$; da expressão " $\psi b$ "; e assim por diante. Um nome, no Tractatus, é uma constelação de possibilidades combinatórias elementares girando em torno de uma "relação afigurante" (abbildende Beziehung), que faz a ligação entre os elementos da figuração e as coisas (2.1514). Isso fica bastante claro se nos perguntarmos o que é o nome correspondente ao sinal "a" na proposição " $F[f(x, y)$, a ] v $\mathrm{f}(\mathrm{a}, \mathrm{b}) "$. O nome, nesse caso, não é nem exclusivamente 
" $\Phi[\varphi(x, y)$, a $] \vee \varphi(x, y) ", \quad$ nem $\quad \Phi[\varphi(x, y), x] \vee \varphi(a, y) " . \quad$ Na proposição que estamos considerando existem duas possibilidades elementares de combinação envolvendo o sinal "a": "$\Phi[\varphi(x, y)$, a ]" e " $\varphi(a, y) "$. Essas duas possibilidades devem estar prefiguradas no nome, pois apresentam, na linguagem, duas possibilidades combinatórias desse objeto. Tanto "Ф[ $\varphi(x, y)$, a ]" quanto " $\varphi(a, y) "$ são "seções" de um mesmo nome - o nome que, por questões de conveniência, podemos representar simplesmente com a letra "a". Da mesma maneira, podemos representar com as letras "x", "y", "z", etc., as variáveis que podem ser substituídas por esse nome. A rigor, porém, no caso da proposição "F[ $f(x, y)$, a ] v f(a,b)", essas variáveis são as expressões

$$
\begin{aligned}
& \text { "F[f(x,y), x ] v f(a,b)" } \\
& \text { "F[f(x,y), a ] v f(x,b)" } \\
& \text { "F[f(x,y), a ] v f(y,b)" }
\end{aligned}
$$

etc.

que Wittgenstein chama de "nomes variáveis". O nome que abreviadamente designamos por "a" deve ser visto, portanto, como o complemento de cada um desses "nomes variáveis" - no primeiro caso, a expressão

$$
\text { "Ф[ } \varphi(x, y), \text { a }] \vee \varphi(x, y) "
$$

e, no segundo caso,

$$
\text { "Ф[ } \varphi(x, y), \text { x ] v } \varphi(a, y) " .
$$

Tanto a primeira quanto a segunda expressão devem ser vistas como "seções" de um mesmo nome, ou seja, como duas possibilidades de combinação constitutivas de um mesmo 
nome.

A especificação das possibilidades elementares de combinação esgota, na verdade, a sintaxe lógica de um nome. Foi isso que nos fez caracterizar a nomeação, no Tractatus, como uma constelação de possibilidades elementares de combinação girando em torno de uma única "relação afigurante". Proposições moleculares são formadas pela aplicação de funções de verdade a totalidades formalmente determinadas de proposições, e essa aplicação, no Tractatus, é feita de maneira absolutamente uniforme ${ }^{10}$. Dadas duas proposições quaisquer, será sempre possível fazer a conjunção de ambas; dada a totalidade de valores de uma expressão como "F[ $f(x, y), \mathbf{x}] \mathbf{v} f(a, b) "$, será sempre possível negar a totalidade desses valores; e dada a totalidade de membros de uma série formal como "não há pessoas nesta sala", "há exatamente uma", "há exatamente duas", etc., será sempre possível também negar simultaneamente todos eles ${ }^{11}$. Essas possibilidades são perfeitamente indiferentes aos nomes que ocorrem no interior das proposições elementares usadas na construção de proposições cada vez mais complexas. Tudo que diz respeito à "forma lógica" de um nome pode ser obtido, no Tractatus, no nível das proposições elementares.

De certo ponto de vista, essa abordagem não está tão distante assim da sintaxe lógica apresentada nos Principia Mathematica. Russell adota uma notação que obriga o nome a possuir uma estrutura que explicita uma parte importante de sua sintaxe. Todo nome, nos Principia, carrega consigo

\footnotetext{
${ }^{10}$ A situação altera-se completamente com o abandono do princípio de independência das proposições elementares, em 1929. Cf. Some Remarks on Logical Form.

${ }^{11}$ Obtendo, assim, a proposição "há infinitas pessoas nesta sala".
} 
uma indicação do tipo a que pertence cada um de seus argumentos possíveis. No caso de um nome de indivíduo, não temos nenhuma indicação, já que nomes de indivíduos não admitem argumentos. Mas nomes de funções sempre trazem uma indicação referente ao tipo dos argumentos. É o que acontece, em nosso exemplo, com "f(x,y)" e "F[ $\varphi(x, y), x]$ ". As letras em itálico (que nos Principia são substituídas por letras com um acento circunflexo) indicam o tipo correspondente a cada argumento ${ }^{12}$. Nessa notação, vemos claramente que a função proposicional que poderíamos abreviadamente chamar de " $\mathrm{f}$ " toma argumentos do mesmo tipo que as variáveis individuais "x" e "y"; e a função proposicional que poderíamos abreviadamente chamar de "F" toma dois argumentos - o primeiro deles é uma função cujos argumentos são do mesmo tipo que as variáveis individuais "x" e "y", e o segundo é, ele próprio, do mesmo tipo que uma variável individual. É bem verdade que as diferenças com respeito ao Tractatus também são marcantes. Um nome, nos Principia, traz apenas as marcas de seus argumentos possíveis, dos argumentos de seus argumentos, e assim por diante, até o nível das variáveis individuais. Não traz, porém, a marca de suas ocorrências possíveis. Nada, por exemplo, me permite "enxergar" no nome "f(x,y)" a possibilidade de sua ocorrência como argumento do nome "F[ $\varphi(x, y), x]$ ]"; é apenas neste último nome que aquela possibilidade pode ser "antevista". Tomados em conjunto, os nomes da linguagem apresentam todas as possibilidades de combinação. A ordenação dos "tipos lógicos" pode ser completamente apresentada pela totalidade dos nomes, graças

${ }^{12}$ Cf. Principia, p. 14-15. 
ao caráter hierárquico dessa ordenação. Cada nome exibe suas possibilidades de combinação com nomes de entidades que estão "abaixo" dele mesmo na hierarquia. Suas possibilidades de combinação com nomes de entidades que estão acima dele na hierarquia serão apresentadas por esses nomes. Visto de cima, o "sistema dos nomes" apresenta todas as possibilidades, determinando, assim, o "espaço lógico" daquilo que pode ser dito na linguagem dos Principia.

No Tractatus, o espaço lógico também está totalmente determinado pela forma lógica dos nomes, vale dizer, por suas possibilidades e impossibilidades combinatórias. Dada a sintaxe lógica que preside a formação das proposições elementares, estarão dados todos os estados de coisas possíveis, e é a totalidade destes que Wittgenstein chama de "espaço lógico". Desse ponto de vista, não há diferença entre o Tractatus e os Principia. O que faz com que as concepções lógicas e ontológicas de Russell e Wittgenstein sejam absolutamente antagônicas é o modo de determinar o espaço lógico. Aos olhos de Wittgenstein, a teoria dos tipos de Russell é a um só tempo dispensável, arbitrária e absurda. Vejamos por quê.

A ordem combinatória vigente no interior da linguagem é determinada, nos Principia, por duas decisões analíticas perfeitamente ajustadas uma à outra. A primeira decisão analítica é uma herança direta de Frege. Trata-se da velha distinção entre função e objeto, entre entidades "saturadas" e "insaturadas". Objetos (ou "indivíduos", como Russell prefere chamá-los) são saturados, vale dizer, podem "ser argumentos" de determinadas funções, mas jamais "tomam" argumentos de espécie alguma. Nomes de objetos devem ser vistos como "saturados" no mesmo sentido - podem ser usados como complementos adequados de certas expressões 
funcionais. Essas expressões funcionais são "insaturadas" porque exibem essa possibilidade ausente no caso dos nomes de objetos - elas são capazes de "tomar" argumentos para formar proposições completas. A assimetria entre o que é "saturado" e o que é "insaturado" determina o caráter absolutamente peculiar das entidades que encontramos no "primeiro andar" do edifício dos tipos. Mais precisamente, essa assimetria determina o fato mesmo de haver um primeiro andar no edifício. Se todas as entidades fossem insaturadas, elas só poderiam organizar-se hierarquicamente caso houvesse infinitos graus tanto abaixo quanto acima de qualquer nível dado, já que, pela teoria dos tipos, os argumentos de uma função devem ser buscados em graus necessariamente inferiores da hierarquia. A existência desse "andar térreo" é possibilitada pela assimetria determinada pelo par saturado/insaturado, que opõe em bloco os indivíduos russellianos às funções proposicionais de diversos tipos e ordens.

A segunda decisão analítica coincide com a reprodução da ordem hierárquica no universo das funções. Funções não apenas "tomam" argumentos, como também podem "ser" argumentos de funções de ordem superior. É isso que nos dá todo o restante do edifício dos tipos. A hierarquização das funções de acordo com o tipo de argumento que admitem (e, no interior de cada "pavimento", de acordo com as quantificações que envolvem) foi justificada por Russell por intermédio do "princípio do círculo vicioso" tudo que envolve todos os elementos de uma coleção não pode ser parte da coleção ${ }^{13}$. Funções de primeira ordem

${ }^{13}$ Cf. Principia, p. 37. 
"envolvem" todos os argumentos possíveis e, por isso mesmo, não podem fazer parte da coleção desses argumentos. Devem tomar argumentos "no andar de baixo" e só podem ser argumentos de funções superiores. O princípio, no entanto, é só um remendão teórico que tenta fundamentar uma teoria cujas motivações eram nitidamente pragmáticas. A teoria dos tipos, para Russell, era boa porque permitia livrar o logicismo - e, de maneira geral, a própria lógica - de paradoxos como o que ele mesmo descobrira. $\mathrm{O}$ importante era evitar a qualquer custo (em última instância - proibindo...) sentenças como " $F(F) "$. Dadas as circunstâncias, aliás, a exigência de um "princípio fundamentador" da teoria dos tipos nem chegava a ser tão premente. $O$ principal problema de Russell, afinal, não era a falta de princípios, mas o excesso deles. Acrescentar o princípio do círculo vicioso na introdução geral dos Principia poderia dar um pouco mais de cogência à teoria dos tipos, mas deixar esse mesmo princípio de lado não acarretava maiores danos ao projeto logicista como um todo. Nenhuma dedução do livro depende dele. O mesmo não se pode dizer do axioma da redutibilidade, sem o qual, nos Principia, não é possível nem mesmo formular o princípio da identidade dos indiscerníveis ${ }^{14}$. $\mathrm{O}$ mesmo vale para o axioma da infinitude. Russell não foi levado a acrescentar esses dois princípios para tornar o sistema todo mais cogente. Sem eles, da maneira como o formulou, seu sistema simplesmente não funciona. A hie-

\footnotetext{
${ }^{14} \mathrm{O}$ princípio aparece, na verdade, na forma de uma definição, em * $13.01: x=y .=:(\varphi): \varphi ! x \cdot \supset . \varphi ! y$ Df. A quantificação está restrita às funções "predicativas" (que não envolvem nenhuma variável que não venha do andar imediatamente inferior do edifício dos tipos). O princípio se estende às funções não predicativas caso a caso, por intermédio do axioma da redutibilidade. Torna-se possível, então, reduzir ao absurdo a ideia de que exista uma função não predicativa $\psi x$ tal que $\mathrm{x}=\mathrm{y}, \psi \mathrm{x}$ e, apesar disso, $\sim \psi$ y. $\mathrm{O}$ axioma me garante a existência de uma função predicativa equivalente a $\psi x$, e essa função predicativa cai no escopo da definição de identidade dada acima.
} 
rarquia dos tipos, portanto, não é "deduzida" de princípios lógicos mais elementares, como o princípio do círculo vicioso. Ela é uma sintaxe lógica assentada na distinção fregeana entre funções e objetos e orientada no sentido de evitar a todo custo a ocorrência de paradoxos no interior do sistema.

Wittgenstein acusa a teoria dos tipos de ser "arbitrária" $^{15}$. Ela apresentaria os elementos últimos da linguagem não como o resultado de um processo de análise, mas como um pressuposto geral desse processo. Como ficou dito anteriormente, a hierarquia dos tipos não é algo que achamos após um paciente trabalho de análise das proposições da linguagem cotidiana. Muito pelo contrário, ela é, para Russell, o alicerce indispensável de qualquer linguagem que se queira "logicamente perfeita". Sem a hierarquia dos tipos, a conceitografia estará condenada a produzir paradoxos, tornando-se, por isso mesmo, inutilizável como suporte de um sistema axiomático qualquer. A lógica não determina o que vem a ser os "indivíduos" que estão na base da hierarquia. Feita essa determinação, no entanto, a lógica tem uma resposta pronta para a pergunta a respeito da natureza de todas as outras entidades de que os fatos, em última análise, são constituídos - essas entidades são, segundo nos garante a teoria dos tipos, propriedades e relações entre indivíduos, propriedades dessas propriedades, relações entre elas, e assim por diante. A ontologia esboçada pelos Principia está assentada, portanto, na análise lógica da linguagem, exatamente como irá acontecer com a ontologia prometida

\footnotetext{
${ }^{15}$ Mais explicitamente em 5.554: "A indicação de quaisquer formas específicas seria completamente arbitrária". No aforismo seguinte (5.5541) encontramos a referência irônica à necessidade de um sinal correspondente a uma relação com 27 termos.
} 
pelo Tractatus. Para Wittgenstein, no entanto, a ontologia dos Principia está marcada desde o início por uma completa arbitrariedade. Os "elementos últimos" de que o mundo é composto seriam as referências dos "elementos últimos" de que uma linguagem logicamente perfeita, como a dos Principia, é composta. A hierarquia que está na base dos Principia, no entanto, só se justifica por ser uma das maneiras não a única, certamente - de se evitar o surgimento de paradoxos no interior de sistemas axiomáticos.

Além disso, se for reduzida a um conjunto de regras que proíbem determinadas combinações sintáticas, ela não introduz nenhum elemento que não pudesse ser introduzido por uma "teoria correta do simbolismo". A face "puramente sintática", digamos assim, da teoria dos tipos pode ser resumida na afirmação de que "nenhuma proposição pode dizer algo a respeito de si mesma, pois o sinal proposicional não pode estar contido nele mesmo" (3.332). No caso das proposições elementares, vistas "fregeanamente" como o preenchimento de certa função por certos argumentos, o que devemos evitar é que uma função possa ser seu próprio argumento. A teoria dos tipos, entendida como mero "regulamento sintático", é absolutamente eficiente para evitar essa situação. Eis como o próprio Wittgenstein descreve seu funcionamento: "Suponhamos, por exemplo, que a função $F(f x)$ possa ser seu próprio argumento. Nesse caso, teríamos a proposição " $F(F(f x))$ " e, nela, a função $F$ mais externa e a função $F$ mais interna devem possuir significados diferentes, já que a mais interna tem a forma $\varphi(f x)$ e a mais externa tem a forma $\psi(\varphi(f x))$. $O$ que as duas funções têm em comum é apenas a letra "F", que sozinha não significa nada" (3.333). Russell concordaria em gênero, número e grau. É assim mesmo que, em última instância, a teoria 
dos tipos atuaria na prevenção dos paradoxos. Cada função carrega consigo a forma de seus argumentos possíveis, e isso faz com que ela não possa aparecer entre esses argumentos $^{16}$. O problema é que não é necessário postular a hierarquia dos tipos para podermos ter acesso a esse resultado. $\mathrm{O}$ dito contextual de Frege - wittgensteinianamente interpretado - é mais do que suficiente. Em qualquer linguagem na qual o nome carregue consigo a marca de suas possibilidades de combinação será impossível pretender que um sinal como "F(F)" atribua a propriedade F a si mesma. Será sempre necessário distinguir, no contexto proposicional, a primeira ocorrência da letra " $F "$ da segunda.

No entanto, o foco das críticas de Wittgenstein à teoria dos tipos não diz respeito ao fato de ela ser supérflua ou arbitrária. Segundo o Tractatus, ela é, antes de mais nada, absurda. Ela seria uma tentativa de descrever a sintaxe lógica da linguagem falando a respeito dos significados dos sinais, e não dos próprios sinais. "Na sintaxe lógica", diz Wittgenstein,

o significado [Bedeutung] de um sinal não deve desempenhar nenhum papel. Devemos poder estabelecê-la sem falarmos a respeito dos significados [Bedeutungen] dos sinais. Ela deve pressupor apenas a descrição [Beschreibung] das expressões (3.33).

A primeira coisa a ser notada, nesse trecho, é que Wittgenstein admite sem hesitação a possibilidade de (i) estabelecer a sintaxe lógica de uma linguagem e de (ii) descrever essa sinta-

\footnotetext{
${ }^{16}$ A teoria, é claro, não se resume a uma regulação dos argumentos possíveis de uma função. Boa parte dela diz respeito à impossibilidade de nos referirmos (via quantificação) à totalidade das funções que tomam argumentos de certo tipo. Segundo Russell, só funções "predicativas" formam totalidades legítimas, e é só a elas que os quantificadores de ordem superior podem se referir. No aforismo 3.333, no entanto, Wittgenstein tem em vista a situação mais elementar visada pela teoria.
} 
xe. Se quisermos chamar a esse tipo de descrição de "metalinguagem", então devemos reconhecer que o Tractatus jamais excluiu a possibilidade de um discurso "metalinguístico". O que se exclui, isso sim, é a possibilidade de nos referirmos à relação entre o nome e o objeto que ele nomeia. A linguagem enquanto ordem combinatória a ser observada no uso de certos sinais é tão descritível quanto o jogo de xadrez ou a teoria musical. O Tractatus se acomoda bastante bem àquilo que chamamos, na sintaxe, de "regras de formação". O problema surgiria apenas no nível das regras semânticas. $O$ que não podemos dizer, definitivamente, é que "'neve' significa neve", ou que "'A neve é branca' é verdadeira se (e somente se) a neve é branca". "Verdade" e "significado" são o que o Tractatus chama de "conceitos formais". São constitutivos da linguagem, mas não podem ser objeto de uma descrição linguística. É esse o pecado capital da teoria dos tipos. "O erro de Russell", diz Wittgenstein, "mostra-se no fato de ter precisado falar dos significados dos sinais ao estabelecer as regras para esses sinais [Zeichenregeln]".

À primeira vista essa acusação pode parecer injusta, mas, bem vistas as coisas, é justíssima. As confusões feitas por Russell nos Principia entre sinais e aquilo que esses sinais significam são proverbiais. É difícil estabelecer o que se entende ali por "função proposicional", ou mesmo por "proposição". Uma palavra como "indivíduo" parece fortemente associada à contraparte ontológica dos nomes que estão na base da hierarquia, enquanto "função proposicional", "argumento" e "proposição" parecem posicionados no interior das fronteiras do "sistema de sinais" que, segundo o Tractatus, pode ser descrito sem nenhum problema. Veja-se, porém, como esses conceitos se misturam na definição re- 
cursiva dada por Russell da relação "ser do mesmo tipo que $^{\prime 17}$ :

Dizemos que $u$ e $v$ "são do mesmo tipo" se

(1) ambos são indivíduos

(2) ambos são funções elementares que tomam argumentos do mesmo tipo

(3) $u$ é uma função e v é sua negação

(6) ambas são proposições elementares

etc.

Poderíamos pensar que a única coisa que daria razão a Wittgenstein, nesse trecho, é um uso infeliz da palavra "indivíduos" em (1). Se substituirmos essa palavra pela expressão "nomes de indivíduos", a definição passa a dizer respeito exclusivamente aos sinais da linguagem e ficaria inobjetável aos olhos do Tractatus. Afinal de contas, como já vimos, a descrição dos aspectos puramente sintáticos de uma linguagem não é mais problemática que a descrição dos movimentos permitidos e proibidos de um jogo qualquer. Não haveria por que atribuir a Russell o erro de "ter precisado falar do significado dos sinais ao estabelecer as regras para esses sinais". Russell, dados os devidos descontos, teria falado apenas de sinais, e a acusação de Wittgenstein só poderia dever-se a um apego excessivo à letra, e não ao espírito do texto.

Independentemente das reais intenções de Russell, é perfeitamente possível formular toda a teoria dos tipos na forma de regras metalinguísticas de construção. Se todo o problema se resumisse a essa constatação, deveríamos reconhecer de pronto que Russell não estava "obrigado" a falar a

$17 * 9.131$. 
respeito do significado dos sinais quando estabeleceu as regras de construção para a linguagem dos Principia. Ainda que ele tivesse extrapolado os limites estritos da sintaxe, seria sempre possível mostrar que seu projeto não envolvia essa extrapolação de modo essencial. Mas o problema, nesse ponto, é outro. Do ponto de vista de Wittgenstein, o que diferencia seu projeto de análise daquele dado por Russell nos Principia é justamente o fato de este último incorporar de antemão uma especificação das formas de todas as proposições elementares. Como vimos anteriormente, o espaço lógico não é, para Russell, um resultado da análise, mas seu pressuposto. A lógica de Russell começa exatamente no ponto em que a lógica do Tractatus pretendia culminar - na apresentação do elenco completo dos nomes de que a linguagem é composta, juntamente, é claro, com as possibilidades combinatórias que esses nomes incorporam. Essa apresentação seria dada com a apresentação do elenco completo das proposições elementares a partir das quais toda e qualquer descrição poderia ser construída. Essas proposições elementares apresentariam, por sua vez, possibilidades discretas no espaço lógico - estados de coisas que podem estar realizados no mundo ou não. $O$ sentido dessas proposições elementares não estaria em jogo. Não se rata, portanto, de apresentar, no final do processo de análise, uma série de sinais cuja significação seria determinada em um momento lógico diverso. Trata-se, muito pelo contrário, de apresentar um conjunto de proposições plenamente significativas constituídas por concatenações imediatas de nomes. A apresentação dessa totalidade de proposições significativas coincide, para Wittgenstein, com a apresentação da totalidade dos nomes já associados a suas "referências". A sintaxe lógica do Tractatus pode se dar ao 
luxo de dispensar a discriminação das referências dos nomes porque estas seriam exibidas ao final do processo de análise.

Nos Principia, a discriminação da totalidade dos nomes é um movimento inicial do jogo da análise. Nenhuma significação está dada até ali. Temos a impressão de que essas significações estão dadas simplesmente porque projetamos sobre a hierarquia dos tipos as noções de "sujeito" e "predicado" da linguagem cotidiana. Sabemos que "Sócrates" não é um nome, no sentido lógico do termo, pois apresenta os mesmos problemas que uma expressão designadora como "o professor de Platão". Também sabemos que a mortalidade deve revelar-se tão carente de uma análise em termos de "átomos lógicos" quanto o próprio Sócrates. Apesar disso, tratamos "Sócrates é mortal" como análogo, em alguma medida, a proposições da conceitografia, como "fa", para as quais ainda não temos uma interpretação definitiva - "fa" será a atribuição de uma "propriedade" a um "indivíduo", da mesma forma que na proposição anterior temos a atribuição da mortalidade a Sócrates. Esperamos, então, que um nome como "a" nomeie algo parcialmente análogo a Sócrates (um "indivíduo") e que "fx" nomeie algo parcialmente análogo a "x é mortal" (ou ao substantivo abstrato "mortalidade"). É só por isso que a sintaxe baseada na teoria dos tipos ganha sentido e parece perfeitamente razoável.

Imaginemos que Russell não tivesse falado em lugar nenhum a respeito de "indivíduos", "propriedades de indivíduos", "relações entre indivíduos", e assim por diante. Suponhamos que ele fizesse uma apresentação puramente sintática de sua "linguagem", referindo-se a "sinais de tipo 
0", "sinais de tipo 1", "sinais de tipo 2", e assim por diante ${ }^{18}$. A arbitrariedade da solução de Russell, disfarçada pela analogia com as formas dos enunciados da linguagem ordinária, ficaria escancarada. Todo o projeto logicista dos Principia estaria condenado ao fracasso caso não tivéssemos boas razões para acreditar que as sentenças descritivas da linguagem cotidiana pudessem ser traduzidas naquela conceitografia. De nada adiantaria reconstruir, nessa linguagem artificial, sentenças que guardassem uma semelhança estrutural com sentenças da aritmética como " $5+7=12$ ", caso não tivéssemos boas razões para acreditar na possibilidade de traduzir, nessa mesma linguagem, sentenças como "Há 5 pessoas nesta sala". Um logicismo que se contentasse com um jogo vazio de sinais estaria exposto às mesmas críticas que, desde Frege, os logicistas dirigiam ao formalismo - ficaria difícil explicar, por exemplo, qual é a conexão existente entre os jogos simbólicos da aritmética e as inferências que fazemos utilizando números. E se tudo fosse mesmo uma questão de tomar um jogo simbólico e não interpretado de modo primitivo, as ginásticas conceituais exigidas pelas definições de Frege pareceriam um trabalho inútil. Para que definir "0" em termos de sinais de tipo 1, tipo 2, etc., se estamos desde o início dispostos a lidar com a linguagem que usa esses sinais como um jogo não interpretado? Melhor ficar com o jogo da aritmética tal como o aprendemos na escola elementar...

Ainda, portanto, que modificássemos o texto de Russell de maneira a fazer com que a teoria dos tipos se referisse apenas a entidades sintáticas, isso não resolveria o problema. Em algum ponto deveríamos ancorar aquela análise em

\footnotetext{
${ }^{18}$ A rigor, os tipos deveriam ser designados por $n$-plas ordenadas.
} 
estruturas familiares da linguagem cotidiana que ao menos prometessem, no final do processo, uma tradução sistemática de todas as descrições possíveis. Se tudo que soubéssemos fosse que essas descrições deveriam ser feitas em termos de sinais de tipo 1 , sinais de tipo 2 , etc., não teríamos nenhuma razão para acreditar que o processo poderia ser levado a bom termo. É fundamental, por isso, que Russell refira-se a indivíduos, propriedades de indivíduos, e assim por diante. Sem essa referência, o projeto logicista fica reduzido a um formalismo prolixo repleto de malabarismos inúteis.

Acredito, portanto, que Wittgenstein tinha toda razão em dizer que, ao formular as regras referentes aos sinais, Russell estava obrigado a mencionar a referência destes. Ele se obriga a isso a partir do momento em que elenca a totalidade desses sinais anteriormente aos resultados da análise. Ao elencá-los, ele não dispõe de nenhuma proposição significativa que empregue tais sinais. Não dispondo dessa proposição, o significado desses sinais não pode ser dado "no contexto da proposição". Não podendo ser dado assim, tem que ser "insinuado", ou "esboçado" de alguma forma, para não reduzir o logicismo a um formalismo particularmente tolo. É nesse momento que a linguagem cotidiana empresta suas categorias ("indivíduos", como Sócrates, "propriedades de indivíduos", como a mortalidade, etc.) para que os sinais de tipo 1, tipo 2, etc., recebam um preenchimento precário, que análises epistemológicas ulteriores tratarão de refinar.

No Tractatus, tudo é diferente. Quando os nomes entram em cena, eles já vêm preenchidos de significação. As proposições elementares que encontramos no final da análise exibem, naquilo que elas dizem, quais são os nomes de que toda e qualquer linguagem é composta, qual é a ordem 
combinatória vigente entre eles e qual é o objeto que cada um deles designa. Não é preciso "insinuar", nem "esboçar" significações. Elas estão ali, absolutamente visíveis. A sintaxe pode aplicar-se sobre os sinais sem a preocupação de sussurrar uma semântica ao leitor. É fazer o exercício de descrever a ordem sintática de certa apresentação sensorialmente perceptível do pensamento sem incorrer no contrasenso de se pensar as condições de possibilidade de todo e qualquer pensamento. $\mathrm{O}$ que estarei descrevendo, na sintaxe lógica da linguagem, é um jogo de sinais, sem interpretação nenhuma, mas que tem o lastro de todo o trabalho de análise que a antecedeu. A teoria dos tipos é simplesmente um jogo sem lastro nenhum, um tiro no escuro, um lance de dados, que só pode estar certa por um acaso, cuja ocorrência só uma análise verdadeira, nos moldes preconizados no Tractatus, teria a oportunidade de constatar.

Devemos, portanto, reconhecer a precariedade da exposição que fizemos até aqui da lógica do Tractatus. Na falta de exemplos retirados de uma análise completa da linguagem que o Tractatus nunca fez, e que acabou se revelando uma quimera inalcançável, utilizamos exemplos decalcados do espaço lógico dos Principia. É preciso corrigir a situação impondo um enorme mutatis mutandis a tudo que foi dito até aqui. Quando dizíamos, por exemplo, que o nome que se une a "F[f(x,y), a ] v $f(a, y)$ " para formar a proposição "F[ $f(x, y)$, a ] v f(a,b)" não é a letra "b" tomada isoladamente, mas sim a expressão "$\Phi[\varphi(x, y), \mathbf{x}]$ v $\varphi(x, b) "$, isso é verdade, mas apenas mutatis mutandis. É preciso imaginar que, no lugar dessas sentenças lavradas na linguagem da teoria dos tipos, temos outras, lastreadas pelo trabalho de análise. Como nesse caso o estranhamento pode ser instrutivo, suponhamos que esse trabalho tivesse sido levado a termo. 
Todas as proposições elementares da linguagem seriam formadas pela concatenação imediata de nomes pertencentes a três categorias. Em certo sistema de representação, os nomes da primeira categoria seriam introduzidos pelos sinais "a", "a*", "a**", etc.; os da segunda categoria, pelos sinais "A", "A*", "A**", etc.; os da terceira, pelos sinais " $\alpha$ ", " $\alpha$ ",

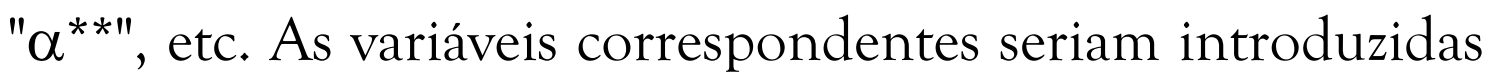
pelos sinais "x", "x*", etc., "X", "X", etc. e " $\Phi ", ~ " \Phi * "$, etc. Nessa notação,

$$
\mathrm{a} \mathrm{A}^{* *} \alpha^{*}
$$

seria uma típica proposição de nossa linguagem. E o que dissemos a respeito da proposição " $F[f(x, y)$, a ] v f(a,b)" continua valendo nesse novo contexto. Podemos ver (I') como a união imediata do "nome variável"

$$
\mathrm{aX} \alpha^{*}
$$

com a expressão

$$
\mathrm{xA}^{* *} \Phi \quad(\mathrm{III})
$$

É "xA** $\Phi$ ", e não o sinal gráfico "A" que o Tractatus chamaria de "nome". Caso houvesse outras possibilidades combinatórias associadas ao sinal "A", além de sua ocorrência em proposições elementares da forma "xX $\Phi$ ", deveríamos dizer, com mais exatidão, que "xA** $\Phi$ " é a "seção de um nome", pelas razões já expostas. $\mathrm{O}$ nome, no sentido pleno da palavra, seria dado pela constelação de possibilidades sintáticas associadas ao sinal "A". Em todo caso, o que nomeia, na proposição "aA** $\alpha^{* "}$, não é o sinal "A", mas sim a expressão "xA $A^{* *} \Phi "$, que é uma variável proposicional, e pode, como queríamos demonstrar, ser negada sem nenhum problema. 
Abstract: In the Tractatus Logico-Philosophicus, a name is always a propositional function. Wittgenstein makes a radical shift in the Fregean opposition between saturated and unsaturated entities. Any sentential component which is not itself a sentence is unsaturated. The proposition is therefore a synthesis of propositional functions. The name is just a limit case of propositional function, and as such it can be negated.

Keywords: philosophy of language, philosophy of logic, negation, propositional function, name, Wittgenstein, Tractatus Logico-Philosophicus.

\section{REFERÊNCIAS}

WITTGENSTEIN, L. Tractatus Logico-Philosophicus. Tradução e ensaio introdutório de Luiz Henrique Lopes dos Santos. São Paulo: Edusp, 1993. 